\title{
Frequency of Computer Vision Syndrome \& Ergonomic Practices among Computer Engineering Students
}

\author{
Hafiz Muhammad Junaid Hassan ${ }^{1}$, Sarah Ehsan ${ }^{2}$, Hafiz Sheraz Arshad ${ }^{3}$ \\ ${ }^{1}$ Physical Therapist, Department of Physical therapy, The Superior College, Lahore, Pakistan \\ ${ }^{2}$ Senior lecturer, Azra Naheed Medical College, Department of Physical Therapy, Main Raiwind Road, Lahore \\ ${ }^{3}$ Head of Department/Assistant professor, Azra Naheed Medical College, Department of Physical Therapy, Main Raiwind Road, Lahore
}

\begin{abstract}
The aim of this study was to assess the frequency of CVS \& related ergonomic practices among computer engineering students. A cross sectional study was conducted among computer engineering students of Superior University. A self-administrated questionnaire to assess computer vision syndrome and UC computer checklist was used. Simple randomized technique was used. A Sample of 170 computer engineering students was taken from a population of 1250 students of computer engineering department. All collected data were entered in computer program SPSS version 20 and analyzed through this software. For categorical variable frequency and percentage were used and for discrete variables mean and standard deviation were used. The frequency of CVS was found to be $72.4 \%$ (123/170). Average duration of computer use was 2-5 hours by most of the students (n=109, 64.1\%). About 45.9\% (78/170) students were using computers more than 50 hours a week. (70.0\%) students reported forward leaning posture to clearly see characters on the screen situation. Regarding the back posture out of 1700 ly 28 (16.5\%) students were employing Good Posture. This study concludes that computer vision syndrome is a highly frequent condition among computer engineering students. The results of selfreported ergonomic analysis of computer use revealed that majority of the students were not practicing the correct ergonomic principles.
\end{abstract}

Keywords: Computer vision syndrome, Computers, Computer users, Students, UC checklist

\section{Introduction}

\subsection{Overview}

Many technologies like computer, laptops, television, cell phones, internet, and many other devices show a central role in our private, institutional and excellent lifestyle. The trend of computer use has become worldwide [1]. On one side, these technologies made our lifestyle too much relaxed, but on the other side produce many dangers for human health. The bad hazards of these technologies are increasing their need day by day [2]. By increasing the use of computers in homes, offices, as well as in professional and educational life, there is a requirement to explore whether students, professionals, and other computer users are implementing ergonomic principles when they using these devices [1].

Although, the individuals who use computer for three hours or more on daily basis, can develop many health related medical conditions like computer vision disorder, migraine, backache, cervical pain or stiffness, shoulder pain, psychosocial stress and postural discomfort. These all are the disadvantages of daily computer use [3]. These all problems may be caused by combination of individual visual complications, poor workplace settings and inadequate work routines [4].

Computer Vision Syndrome is a common condition in those people who continually use computers, laptops, cell phones, Internet and other technology devices that stress the eye. It has been calculated that almost sixty million people who practiced vision complications due to computer use in all over the world $90 \%$ of the individuals who use computer three to four hours daily can develop CVS and it can be prevailing with the symptoms of head pain, blurred or double vision, irritation, dry and tired eyes, burning sensation, redness, eye soreness, tiredness, cervical pain, and dizziness. This computer related ophthalmic disorder is known as Computer Vision Syndrome [5].

However numerous readings must show the relation amongst continued use of computer, deprived positions at workplaces \& a number of musculoskeletal discomposure, maximum studies concentrated on European population [3]. No relevant literature was found regarding the effect of computer use on the physical health of Pakistani computer users. There was a cross sectional study method used in 2014 on the incidence of CVS between medical and engineering students of a university located in Chennai. In which engineering students were at higher risk of developing computer vision syndrome [3].

In Qazvin a study was conducted among eleven to eighteen years old students on computer vision syndrome, which belong to the different age groups [6]. So there was less literature available on the incidence and risk factors of CVS in age group of students from 18 to 25 years old.

In 2014 a study has been conducted on typists and data processors to observe the occurrence of self-informed CVS \& linked causes in those who were employed in the university situated in Ethiopia [7].

A study has been performed on wellbeing and health associated problems related to use of computer in students of a college in India [1]. The Current study focused on poor ergonomics during computer use and vision associated ocular discomfort among computer engineering students. 


\section{International Journal of Science and Research (IJSR) \\ ISSN (Online): 2319-7064}

Index Copernicus Value (2013): 6.14 | Impact Factor (2015): 6.391

In 2013 Nigeria, a study was conducted on office workers to find the frequency of computer vision syndrome and its associated risk factors [5].In Pakistan there was a lesser amount of literature available on the occurrence of CVS and related risk factors among students.

\subsection{Objective}

The objectives of the study were:

- To determine the frequency of computer vision syndrome among computer engineering students.

- To determine the ergonomic practices of computer use by the computer engineering students.

\subsection{Rationale}

The rationale was to improve the quality of life of computer engineering students by correcting their ergonomic practices.

\subsection{Operational definitions}

1.4.1. Diagnostic criteria for computer vision syndrome A Self-Administered Computer Vision Questionnaire used to diagnose the computer vision syndrome in participants who undergoing 1 or 2 vision related symptoms in the reaction of working on a computer. These CVS related symptoms was tiredness, soreness of eyes, watering of eyes, eyestrain, irritation in eyes, dryness, double vision/blurring, cervical pain, LBP, pain in shoulder, etc. [8]

\subsubsection{UC Computer Workstation Checklist}

The UC (University of California) computer workstation checklist used as a tool for analysis of computer use related to upper limb ergonomics which has been established and validated. [9]

The UC Computer Use Checklist was mainly established for evaluating non-neutral positions and activities related to computer use in the workplace and it is followed by a handbook. The Checklist takes almost 30 minutes to complete. It was prepared by a sequence of images representing computing postures, behaviors and workplace characteristics. The total score of the checklist was started from 14 and ends at 121 . Here 121 shows that the respondent at high risk of adopting poor computing posture. [10]

\subsection{Materials and methods}

1.5.1. Study design

It was a descriptive cross-sectional survey

\subsubsection{Setting}

Superior University Lahore

\subsubsection{Study population}

Computer engineering students

\subsubsection{Duration of study}

3 months after the approval from institutional review board

\subsubsection{Sample size}

A Sample of 170 computer engineering students was taken from a population of 1250 students of computer engineering department.

\subsubsection{Sampling technique}

Probability, Simple random sampling was used.

\subsubsection{Eligibility}

\subsubsection{Inclusion criteria}

- Data was collected from all undergraduate and postgraduate computer engineering students who were studying in the Superior University under the age group of 18-25 and who used computers for more than 2 hours on a daily basis.

\subsubsection{Exclusion criteria}

- All those computer engineering students who suffered from any chronic illness related to the eyes.

- All computer engineering students having weak eyesight and wearing eyeglasses.

- Students who were unwilling to participate in the study.

\subsubsection{Data collection}

This descriptive cross sectional study was conducted after the approval from institutional review board of concerned institute. The inclusion criteria were fulfilled by all 170 computer engineering students and data were collected after taking consent. All participants filled a self-administrated computer vision questionnaire and UC computer use checklist, in which the name, age, gender, time duration of computer use per day, frequency of rest during computer use, the diagnostic criteria of CVS, and bad posture styles were included. The outcome variables in this study were the prevalence of computer vision syndrome and ergonomic practices among computer engineering students. The study subjects were asked to report and mark any vision or eye related symptom experience (mild, moderate or severe) during computer use.

\subsection{Ethical Consideration}

Data were taken from computer engineering students after an informed consent. It did not affect the patient ethical values; researcher followed all ethics of the medical field.

\subsection{Statistical procedure}

All collected data were entered in computer program SPSS version 20 and analyzed through this software. For categorical variable frequency and percentage used and for discrete variables mean and standard deviation used.

\section{Results}

The majority of Computer Engineering Students were males $(74.71 \%)$. The mean age of computer engineering students in years was $21.11(\mathrm{SD}=1.58)$ while minimum age was 18 and maximum age was 25 years. Average duration of computer use was 2-5 hours by most of the students $(n=109$, $64.1 \%$ ). More than 10 hours of computer use were reported by only 10 respondents. 


\section{International Journal of Science and Research (IJSR) ISSN (Online): 2319-7064}

Index Copernicus Value (2013): 6.14 | Impact Factor (2015): 6.391

Table 1: Frequency of computer vision syndrome

\begin{tabular}{|c|c|c|c|}
\hline \multicolumn{2}{|c|}{} & $\begin{array}{c}\text { Frequency } \\
(\mathrm{N}=170)\end{array}$ & $\begin{array}{c}\text { Percentage } \\
(\%)\end{array}$ \\
\hline $\begin{array}{c}\text { Computer Vision } \\
\text { Syndrome Present }\end{array}$ & Yes & 123 & 72.4 \\
\cline { 2 - 4 } & No & 47 & 27.6 \\
\hline
\end{tabular}

Out of 170 students Computer Vision Syndrome was present in $123(72.4 \%)$ students \& $101(59.4 \%)$ students reported that they started experiencing symptoms within less than five hours of computer us.

Table 2: Average hours of computer use at work and home

\begin{tabular}{|c|c|c|c|}
\hline & & Frequency & Percentage \\
\hline \multirow{3}{*}{ Work } & Less than 10 Hours & 54 & 31.8 \\
\cline { 2 - 4 } & $10-19$ Hours & 57 & 33.5 \\
\cline { 2 - 4 } & $20-29$ Hours & 33 & 19.4 \\
\cline { 2 - 4 } & 30 or More & 26 & 15.3 \\
\hline \multirow{7}{*}{ At Home } & Less than 10 Hours & 59 & 34.7 \\
\cline { 2 - 4 } & $10-19$ Hours & 59 & 34.7 \\
\cline { 2 - 4 } & $20-29$ Hours & 25 & 14.7 \\
\cline { 2 - 4 } & 30 or More & 27 & 15.9 \\
\hline
\end{tabular}

Table 3: Frequency distribution of duration of use of computer per week, longest time of computer use and work sharing

\begin{tabular}{|c|c|c|c|}
\hline & & $\begin{array}{c}\text { Frequency } \\
(\mathrm{N}=170)\end{array}$ & $\begin{array}{c}\text { Percentage } \\
(\%)\end{array}$ \\
\hline \multirow{2}{*}{$\begin{array}{c}\text { Computer use more } \\
\text { than 50 hours per } \\
\text { week }\end{array}$} & Yes & 78 & 45.9 \\
\cline { 2 - 4 } & No & 92 & 54.1 \\
\hline Longest time of use & Less than 1 hour & 53 & 31.2 \\
\cline { 2 - 4 } & More than 1 hour & 117 & 68.8 \\
\hline Work Sharing & Yes & 58 & 34.1 \\
\cline { 2 - 4 } & No & 112 & 65.9 \\
\hline
\end{tabular}

Table 4: Nature of work

\begin{tabular}{|l|l|l|}
\hline & $\begin{array}{l}\text { Frequency } \\
(\mathrm{n}=170)\end{array}$ & $\begin{array}{l}\text { Percentage } \\
(\%)\end{array}$ \\
\hline Continuous Data Entry or Transcription & 25 & 14.7 \\
\hline Composing Written Documents & 49 & 28.8 \\
\hline Graphics Intensive Work & 24 & 14.1 \\
\hline Intermittent Input or Retrieval & 27 & 15.9 \\
\hline More Than One & 45 & 26.5 \\
\hline
\end{tabular}

Table 5: Posture of Head \& Neck during Computer Use

\begin{tabular}{|c|c|c|}
\hline & $\begin{array}{l}\text { Frequency } \\
(\mathrm{N}=170)\end{array}$ & $\begin{array}{l}\text { Percentage } \\
(\%)\end{array}$ \\
\hline A-Correct Posture & 19 & 11.2 \\
\hline B-Neck Forward & 43 & 25.3 \\
\hline C-Too Low Posture & 15 & 8.8 \\
\hline D-Too Far Posture & 18 & 10.6 \\
\hline E-Neck Backward & 9 & 5.3 \\
\hline F-Body Forward \& Neck Backward & 2 & 1.2 \\
\hline More Than One & 64 & 37.6 \\
\hline
\end{tabular}

Table 6: Position of head during computer Use

\begin{tabular}{|c|c|c|}
\hline & $\begin{array}{c}\text { Frequency } \\
(\mathrm{n}=170)\end{array}$ & Percentage (\%) \\
\hline Straight Head & 137 & 80.6 \\
\hline To The Right & 11 & 6.5 \\
\hline To The Left & 4 & 2.4 \\
\hline More Than One & 18 & 10.6 \\
\hline
\end{tabular}

Table 7: Arm support

\begin{tabular}{|c|c|c|c|}
\hline & & $\begin{array}{c}\text { Frequency } \\
(\mathrm{n}=170)\end{array}$ & $\begin{array}{c}\text { Percentage } \\
(\%)\end{array}$ \\
\hline \multirow{2}{*}{$\begin{array}{c}\text { Keyboard } \\
\text { Left }\end{array}$} & Support & 104 & 61.2 \\
\cline { 2 - 4 } & No Support & 66 & 38.8 \\
\hline Keyboard & Support & 104 & 61.2 \\
\cline { 2 - 4 } Right & No Support & 66 & 38.8 \\
\hline Mouse or & Support & 79 & 46.5 \\
\cline { 2 - 4 } Trackball & No Support & 91 & 53.5 \\
\hline
\end{tabular}

Out of 170 computer engineering students $104(61.2 \%)$ supported their arms during keyboard use and 79 (46.5\%) supported their arm during mouse use.

Out of 170 students $86 \quad(50.6 \%)$ students reported "comfortable or good posture" of the shoulder. On the other hand $39(22.9 \%)$ reported "reaching or too far posture" of the shoulder \& the remaining $45(26.5 \%)$ reported "relax or too close posture" of the shoulder.

$102(60.0 \%)$ students were using their elbow in a comfortable position, $30(17.6 \%)$ students were using their elbow in "too close position" \& remaining 38 (22.4\%) students were using their elbow in "too far position".

Table 8: Angle of wrist

\begin{tabular}{|c|c|c|c|}
\hline & & $\begin{array}{c}\text { Frequency } \\
(\mathrm{n}=170)\end{array}$ & Percentage \\
\hline \multirow{2}{*}{$\begin{array}{c}\text { Left } \\
\text { \& Right }\end{array}$} & A-Lower Surface & 29 & 17.1 \\
\cline { 2 - 4 } Keyboard & B-Straight & 59 & 34.7 \\
\cline { 2 - 4 } Hand & C-Extended & 49 & 28.8 \\
\cline { 2 - 4 } & D-Wrist On Edge & 21 & 12.4 \\
\cline { 2 - 4 } & More Than One & 12 & 7.1 \\
\hline
\end{tabular}

During keyboard use 59 (34.7\%) students \& during mouse use $60(35.3 \%)$ students reported "straight" angle of the wrist. On the other hand, about $12.4 \%(21 / 170)$ participants during keyboard use \& $9.45 \%$ participants during mouse use reported their "wrist on edge".

Table 9: Finger flicking, wrist position and dragging during mouse use

\begin{tabular}{|c|c|c|c|}
\hline . & & $\begin{array}{c}\text { Frequency } \\
(\mathrm{N}=170)\end{array}$ & $\begin{array}{c}\text { Percentage } \\
(\%)\end{array}$ \\
\hline Fingers & A-Never & 40 & 23.5 \\
\hline \multirow[t]{2}{*}{ Flicking } & B-Sometimes & 106 & 62.4 \\
\hline & C-Frequently & 24 & 14.1 \\
\hline \multirow{3}{*}{$\begin{array}{l}\text { Best Position } \\
\text { of Both Wrists }\end{array}$} & A-Straight Wrist & 65 & 38.2 \\
\hline & B-Deviate & 85 & 50.0 \\
\hline & C-Bent Outward & 20 & 11.8 \\
\hline \multirow[t]{2}{*}{ Dragging } & Yes & 92 & 54.1 \\
\hline & No & 78 & 45.9 \\
\hline
\end{tabular}

Table 10: Back position During Computer use

\begin{tabular}{|c|c|c|}
\hline & $\begin{array}{c}\text { Frequency } \\
(\mathrm{n}=170)\end{array}$ & $\begin{array}{c}\text { Percentage } \\
(\%)\end{array}$ \\
\hline Good Posture & 28 & 16.5 \\
\hline Adequate Support & 49 & 28.8 \\
\hline Close To Work & 16 & 9.4 \\
\hline Rounded Lower Back & 28 & 16.5 \\
\hline Rounded \& Lost Of Lumbar Curve & 21 & 12.4 \\
\hline More Than One postures & 28 & 16.5 \\
\hline
\end{tabular}

Out of 170 only 28 (16.5\%) reported "Good" Posture \& 49 $(28.8 \%)$ reported "adequate support" posture.45.3\% 


\section{International Journal of Science and Research (IJSR) \\ ISSN (Online): 2319-7064 \\ Index Copernicus Value (2013): 6.14 | Impact Factor (2015): 6.391}

(77/170) students were using headsets and they were safe. About 27.6\% (47/170) students cradled their phone between shoulder and ear \& 27.1\% (46/170) students held their receiver in one hand. Out of 170 students 88 (51.8\%) were using lumber cushions during their computer use.

Table 11: Area of Back Support

\begin{tabular}{|c|c|c|}
\hline & $\begin{array}{c}\text { Frequency } \\
(\mathrm{n}=170)\end{array}$ & Percentage (\%) \\
\hline At Neck Area & 23 & 13.5 \\
\hline Upper Back Area & 51 & 30.0 \\
\hline Lower Back Area & 72 & 42.4 \\
\hline Buttock Area & 15 & 8.8 \\
\hline No Support & 9 & 5.3 \\
\hline
\end{tabular}

Out of 170 students $23(13.5 \%)$ students supported their neck, 51 (30.0\%) supported their upper back, 72 (42.4\%) supported at their lower back, $15(8.8 \%)$ supported in their buttock area which was not good for them.

Table 12: Foot support

\begin{tabular}{|c|c|c|}
\hline & $\begin{array}{c}\text { Frequency } \\
(\mathrm{N}=170)\end{array}$ & Percentage (\%) \\
\hline The Floor & 51 & 30.0 \\
\hline A Footrest & 27 & 15.9 \\
\hline Base Of Chair & 53 & 31.2 \\
\hline Feet Dangling & 39 & 22.9 \\
\hline
\end{tabular}

Most of the participants had their feet supported by the base of the chair ( $\mathrm{n}=53,30 \%)$. The position predisposing to risk (feet dangling) was used by $39(22.9 \%)$ participants.

Table 13: Sitting positions

\begin{tabular}{|l|l|l|}
\hline & $\begin{array}{c}\text { Frequency } \\
(\mathrm{n}=170)\end{array}$ & Percentage \\
\hline Too High Seat Sitting & 8 & 4.7 \\
\hline Wrapping Legs Sitting & 24 & 14.1 \\
\hline Good Posture of Sitting & 33 & 19.4 \\
\hline Too Low Seat Sitting & 7 & 4.1 \\
\hline Crossing Legs Sitting & 16 & 9.4 \\
\hline Stable Sitting & 10 & 5.9 \\
\hline Straight Legs Sitting & 40 & 23.5 \\
\hline More Than One Posture Of Sitting & 32 & 18.8 \\
\hline
\end{tabular}

Out of 170 students only $33(19.4 \%)$ students reported good sitting posture. $40(23.5 \%)$ students reported straight legs sitting and $16(9.4 \%)$ reported cross leg sitting.

On the other hand $24(14.1 \%)$ reported wrapping leg posture of sitting, $8(4.7 \%)$ reported too high seat sitting posture, 7 $(4.1 \%)$ reported too low seat sitting posture, $10(5.9 \%)$ reported stable sitting posture, and $32(18.8 \%)$ reported more than one type of sitting posture.

During computer use $86(50.6 \%)$ students reported bumping into anything while reaching for documents or moving around.

\section{Discussion}

The present study was conducted among computer engineering students and the frequency of computer vision syndrome in the study population was found to be $72.4 \%$. The $75 \%$ participants were male and remaining $25 \%$ were females. Logaraj et al., reported $80.3 \%$ prevalence of computer vision syndrome among medical and engineering college students in chenni [11] Shantakumari et al., reported $94.2 \%$ the highest prevalence of vision related problems in Gulf medical university [12].Reddy et al., reported $89.9 \%$ cvs symptoms in Malaysian university students [13]. Alemayehu, reported $73.9 \%$ of the study participants were found to suffer from CVS [14].

The present study found that students who were using computer for 2 to 5 hours average a day most of them have been developed computer vision syndrome. Akinbinu and Mashalla, reported that participants who spend 6 to $8 \mathrm{~h}$ average daily on the computer experienced more CVS symptoms [15].Rahman and Sanip, in their study reported that those respondents who used computer for more than 5 $\mathrm{h}$ /day were at higher risk of developing CVS [16]. Reddy et al., reported more than 2 hours continuous use of computer was significantly associated with occurrence of CVS symptoms [13].

In our study the most experienced symptoms were headache, eye strain, neck pain, tiredness \& redness of eyes. Logaraj et al., conducted a study in Chennai and reported symptoms of redness, burning sensation, headache, and dry eye, and neck $\&$ shoulder pain [11]. In a previous study of Shantakumari et al., the most common visual problems reported were headache, burning sensation in eyes and dry/tires/sore eyes [12]. Mahalingam et al. reported the most common symptoms in his study like, headache, fatigue and tiredness, burning of eyes, dry eyes, and neck and shoulder pain [12]. Akinbinu and Mashalla, reported the most experienced symptoms were headache and eye strain [15].

Our respondents were relatively young aged with mean aged of 21 years. Rahman and Sanip conducted a study in Malaysia in which the mean age of respondents was 31 years [16]. Khalaj et al. conducted a study in which the mean age was 15.83 years [17].Seshadhri Arumugam et al., conducted a study in which maximum of them were in the age group of less than 30years [18].

The present study found that students were preventing from symptoms of CVS by taking breaks, using eye drops, blinking their eyes, looking at far objects and using radiation filters on computer screen.

Shantakumari et al., reported that the students were facing symptoms due to improper viewing distances from computer screen, filters not being placed on the screens and using computer without taking frequent breaks and some of them prevented by taking breaks, Using of screen filters [19].

Akinbinu and Mashalla, conducted a study in Nigeria in which most commonly used preventive measures were taking regular breaks, regular eye sight checks and using glare screen on computer were selected by the participants [15].Reddy et al. , conducted a study of Malaysian university students who reported looking at far objects in-between work, viewing the monitor below the eye level, massage of eyes, and use of eye drops helped in reducing the symptoms. Taking a rest in-between the work, use of radiation reducing 


\section{International Journal of Science and Research (IJSR) ISSN (Online): 2319-7064 \\ Index Copernicus Value (2013): 6.14 | Impact Factor (2015): 6.391}

filters on the monitor did not help in reducing the symptoms [13].

In present study the majority of students were not aware of the correct posture of head \& neck and back. In a previous study same results were found and majority was not aware of the appropriate ergonomics principles. [20]

\section{Conclusion}

This study concludes that computer vision syndrome is a highly frequent condition among computer engineering students. The results of self-reported ergonomic analysis of computer use revealed that majority of the students were not practicing the correct ergonomic principles.

\section{References}

[1] Logaraj M, Priya VM, Seetharaman N, Hedge SK. Practice of Ergonomic Principles and computer vision syndrome (CVS) among undergraduates students in Chennai. National Journal of Community Medicine. 2013;3(2)

[2] Ellahi A, Khalil MS, Akram F. Computer users at risk: Health disorders associated with prolonged computer use. Journal of Business Management and Economics. 2011;2(4):171-82.

[3] Logaraj M, Madhupriya V, Hegde S. Computer vision syndrome and associated factors among medical and engineering students in chennai. Annals of medical and health sciences research. 2014;4(2):179-85. Epub 2014/04/25.

[4] Assistant Professor HCoN, Swami Rama Himalayan University, Dehradun. computer vision syndrom among nurses. JNEP. 2015.

[5] Akinbinu TR, Mashalla Y. Knowledge of computer vision syndrome among computer users in the workplace in Abuja, Nigeria: University of South Africa; 2012.

[6] Khalaj M, Ebrahimi M, Shojai P, Bagherzadeh R, Sadeghi T, Ghalenoei M. Computer Vision Syndrome in Eleven to Eighteen-Year-Old Students in Qazvin. Biotechnology and Health Sciences. 2015;2(3).

[7] Alemayehu M. Prevalence of Self Reported Computer Vision Syndrome and Associated Factors among Secretaries and Data Processors Who are Working in University of Gondar, Ethiopia. Journal of Biology, Agriculture and Healthcare. 2014;4(15):33-7.

[8] Reddy SC, Low C, Lim Y, Low L, Mardina F, Nursaleha M. Computer vision syndrome: a study of knowledge and practices in university students. Nepalese Journal of Ophthalmology. 2013;5(2):161-8.

[9] Janowitz IL, Gillen M, Ryan G, Rempel D, Trupin L, Swig L, et al. Measuring the physical demands of work in hospital settings: design and implementation of an ergonomics assessment. Applied ergonomics. 2006;37(5):641-58. Epub 2005/10/18.

[10] Chaumont Menendez C, Amick Iii BC, Joe Chang CH, Harrist RB, Jenkins M, Robertson M, et al. Evaluation of two posture survey instruments for assessing computing postures among college students. Work. 2009;34(4):421-30. Epub 2010/01/16.
[11] Logaraj M, Madhupriya V, Hegde S. Computer vision syndrome and associated factors among medical and engineering students in Chennai. Annals of medical and health sciences research. 2015;4(2):179-85.

[12] Mahalingam. COMPUTER VISION SYNDROME AMONG NURSES. JNEP. 2015;1(2):1-5.

[13] Reddy SC, Low C, Lim Y, Low L, Mardina F, Nursaleha M. Computer vision syndrome: a study of knowledge and practices in university students. Nepalese Journal of Ophthalmology. 2013;5(2):161-8.

[14] Mekuriaw Alemayehu AN, Eniyew Tegegne, Yohannis Mule. Prevalence of Self Reported Computer Vision Syndrome andAssociated Factors among Secretaries and Data Processors Who are Working in University of Gondar, Ethiopia. Journal of Biology, Agriculture and Healthcare. 2014;4(2):33-7.

[15] Akinbinu TR, Mashalla Y. Knowledge of computer vision syndrome among computer users in the workplace in Abuja, Nigeria. J Physiol Pathophysiol. 2013;4(4):58-63.

[16] Rahman ZA, Sanip S. Computer user: demographic and computer related factors that predispose user to get computer vision syndrome. International Journal of business, humanities and technology. 2011;1(2):84-91.

[17] Khalaj M, Ebrahimi M, Shojai P, Bagherzadeh R, Sadeghi T, Ghalenoei M. Computer Vision Syndrome in Eleven to Eighteen-Year-Old Students in Qazvin. Biotechnology and Health Sciences. 2015;2(3).

[18] Arumugam S, Kumar K, Subramani R, Kumar S. Prevalence of Computer Vision Syndrome among Information Technology Professionals Working in Chennai. World Journal of Medical Sciences. 2014;11(3):312-4.

[19] Shantakumari N, Eldeeb R, Sreedharan J, Gopal K. Computer Use and Vision. Related Problems Among University Students In Ajman, United Arab Emirate. Annals of medical and health sciences research. 2015;4(2):258-63.

[20] KHAN, R., SURTI, A., REHMAN, R. \& ALI, U. 2012. Knowledge and practices of ergonomics in computer users. JPMA-Journal of the Pakistan Medical Association, 62, 213.

\section{Author Profile}

Hafiz Muhammad Junaid Hassan is Physical Therapist, Department of Physical therapy, The Superior College, Lahore, Pakistan

Sarah Ehsan is Senior Lecturer, Azra Naheed Medical College, Department of Physical Therapy, Main Raiwind Road,, Lahore

Hafiz Sheraz Arshad is Head of Department/Assistant Professor, Azra Naheed Medical College, Department of Physical Therapy, Main Raiwind Road, Lahore 